Bite Marks Attributable to Tyrannosaurus rex: Preliminary Description and Implications Author(s): Gregory M. Erickson and Kenneth H. Olson

Source: Journal of Vertebrate Paleontology, Vol. 16, No. 1 (Mar. 19, 1996), pp. 175-178 Published by: Taylor \& Francis, Ltd. on behalf of The Society of Vertebrate Paleontology Stable URL: https://www.jstor.org/stable/4523705

Accessed: 29-03-2020 13:30 UTC

JSTOR is a not-for-profit service that helps scholars, researchers, and students discover, use, and build upon a wide range of content in a trusted digital archive. We use information technology and tools to increase productivity and facilitate new forms of scholarship. For more information about JSTOR, please contact support@jstor.org.

Your use of the JSTOR archive indicates your acceptance of the Terms \& Conditions of Use, available at https://about.jstor.org/terms

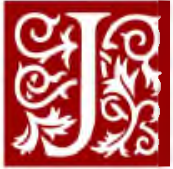

Taylor \& Francis, Ltd., The Society of Vertebrate Paleontology are collaborating with JSTOR to digitize, preserve and extend access to Journal of Vertebrate Paleontology 


\section{BITE MARKS ATTRIBUTABLE TO TYRANNOSAURUS REX: PRELIMINARY DESCRIPTION AND IMPLICATIONS}

GREGORY M. ERICKSON ${ }^{1}$ and KENNETH H. OLSON, ${ }^{2}$ Museum of Paleontology and Department of Integrative Biology, University of California, Berkeley, California 94720: ${ }^{2} 1009$ W. Boulevard, Lewistown, Montana 59457

Fossil bones that bear tooth marks can provide insight into the ecology, behavior, and functional morphology of the taxa that produced them. Such bones may reveal the identity of extinct predators and scavengers and their feeding preferences, the methods they employed to dispatch and consume carcasses (i.e. shearing and nipping flesh, crushing bone, etc.), and the biomechanical capabilities of their jaws and dentitions.

Reports of tooth-marked dinosaur bones are relatively uncommon in the scientific literature (Fiorillo, 1991). Of those instances that have been noted, two in particular relate to Tyrannosaurus rex (Carpenter, 1988; Horner and Lessem, 1993). Carpenter interpreted healed wounds on an Edmontosaurus caudal vertebra as evidence of a failed $T$. rex predation attempt. Horner and Lessem described a Triceratops femur bearing large puncture marks that may have been made by $T$. rex. In this paper, we report two additional specimens exhibiting $T$. rex tooth marks. These observations help to provide a unique glimpse into the feeding behavior of this extinct carnivorous taxon. These findings are of significance because, aside from its participation in intraspecific fighting (McGinnis, 1982; Molnar and Farlow, 1990), virtually nothing is known about $T$. rex behavior.

\section{DESCRIPTION}

Dozens of $T$, rex tooth marks appear on a Triceratops sp. pelvis (sacrum and left ilium) that is housed at the Museum of the Rockies, Bozeman, Montana (MOR 799). This specimen was found by $\mathbf{K} . \mathbf{H}$ Olson in the Late Maastrichtian Hell Creek Formation of east-central Montana. The pelvis bears 58 definitive bite marks and 22 possible others (Figs. 1,2). Many bite marks overlay one another, making an exact count impossible. We suggest that the tooth marks were produced by an adult $T$. rex because of their large size (punctures up to $2.5 \mathrm{~cm}$ in width and $3.7 \mathrm{~cm}$ in depth), their cross-sectional areas are rounded (unlike the more elliptical punctures made by most non-tyrannosaurid theropods whose teeth had lenticular cross-sectional areas: see Farlow et al., 1991), their spacing is wide (>4 cm), and some bones bear coarse serration marks on their periosteal surfaces. Additionally, a cast of one of the deeper bites matches the morphology of an adult $T$. rex lateral tooth (sensu Farlow et al., 1991), including its carina (Fig. 3A, B) Finally, no other known carnivorous animals present in the Hell Creek fauna were large enough to have inflicted comparable damage.

At least thirty-nine puncture marks are located on the ventral and both lateral surfaces of the Triceratops sacrum, showing that it was overturned either prior to or during feeding. Most bites occur on the first sacral vertebra (Fig. 1). It appears the tyrannosaur(s) may have detached the pelvis from the torso by repetitively biting into this centrum, as it has been nearly bitten in half. The majority of these bite marks are in the form of deep localized punctures and appear to have been made by a tyrannosaur's larger anterior lateral teeth. A few elongate bite furrows from shallower biting also appear. The largest is located on the transverse process of the third sacral vertebra and is 1.0 $\mathrm{cm}$ in depth and $11.8 \mathrm{~cm}$ long. Between the transverse processes of two adjacent sacral vertebrae (second and third) are four faint vertically inclined furrows that appear to be nipping marks made by a tyrannosaur's premaxillary teeth. (Unfortunately they show low relief and therefore are not figured here.)

The left ilium of the Triceratops bears at least 19 bite marks on both its ventral and dorsal surfaces (Figs. 1, 2). The bite marks are distributed around the periphery of the iliac crest. Approximately one-sixth of the anterior end of the ilium was bitten off by repetitive bites concentrated in this region. The majority of these bites are furrow-shaped and were likely inflicted by a tyrannosaur's larger anterior lateral teeth. The longest furrow is $0.9 \mathrm{~cm}$ in depth and $10.1 \mathrm{~cm}$ long.

An additional specimen, a proximal pedal phalanx of Edmontosaurus sp. (University of California, Museum of Paleontology; cast 140601) from the same general vicinity as the Triceratops pelvis, shows $T$. rexlike bite marks (i.e. broad and deep elongate bite furrows). The element has five bite mark furrows distributed axially on its dorsal and lateral surfaces (Fig. 4). The largest furrow is $5.4 \mathrm{~cm}$ long and $0.9 \mathrm{~cm}$ deep. The bite furrows are deeper toward the proximal end of the element, suggesting that the tyrannosaur was pulling away from the carcass as it produced the bite marks. No serration marks are evident on the specimen.

\section{DISCUSSION}

Although these specimens do not directly shed light on the predatory or scavenging habits of $T$. rex, they do greatly enhance our understanding of its feeding behavior.

From these specimens it is apparent that on some occasions T. rex fed upon both Triceratops and Edmontosaurus, the two predominant herbivores from the Late Cretaceous Western Interior lowland coastal plains. It is also evident that $T$. rex could produce deep, bone-penetrating bites and that they at least occasionally produced such damage while feeding upon mega-herbivore carcasses. Farlow and Brinkman (1987), Molnar and Farlow (1990), Farlow et al. (1991), and Abler (1992) have previously speculated that the dentition was used in this manner. (How ever, see Halstead and Halstead, [1981] for differing speculations.) These specimens further suggest that when $T$. rex consumed large carcasses, most bite marks on bones were made by their larger anterior lateral teeth. They could also produce shallow furrows using their $U$ shaped complement of anterior premaxillary teeth (see Molnar and Farlow, 1990:fig. 7.7). These marks were probably made when the premaxillary teeth were employed to nip flesh from carcasses. Such incisive biting by mammals produces comparable shallow furrow markings (e.g., Sobbe 1990). When T. rex teeth impacted bones, serration marks were rarely produced. This is unlike smaller theropod dinosaurs whose more laterally compressed teeth left numerous serration marks as the dental carinae contacted bones at acute angles (personal observations of both authors).

A dichotomy is evident in the morphology of the bite marks produced by $T$. rex lateral teeth as they squarely struck bones. The shapes of these marks were likely governed primarily by the thicknesses and structural patterns of the bones themselves. Bites that impacted bones with thin cortices $(<1 \mathrm{~mm}$ thicknesses) and an extensive spongiosa (e.g., sacral vertebrae) produced relatively deep puncture marks. Whereas teeth that impacted bones with thick cortices ( $>2 \mathrm{~mm}$ thickness) and an extensive spongiosa (e.g., ilia) did not penetrate as deeply, and subsequent to the initial bite, the dentition was pulled through the penetrated flesh(?) and bone. Ultimately these bites produced elongate furrows. Such "puncture and pull" biting is reminiscent of the strategy used by the present-day Komodo monitors (Varanus komodoensis), which use their powerful neck musculature and reverse body rocking (i.e., using body mass to full advantage) to dismember large prey items (Auffenberg, 1978, 1981). Bakker (1986) and Molnar and Farlow (1990) have proposed a similar biting strategy for tyrannosaurs.

Based upon the concentrated biting that occurred at the anterior por- 


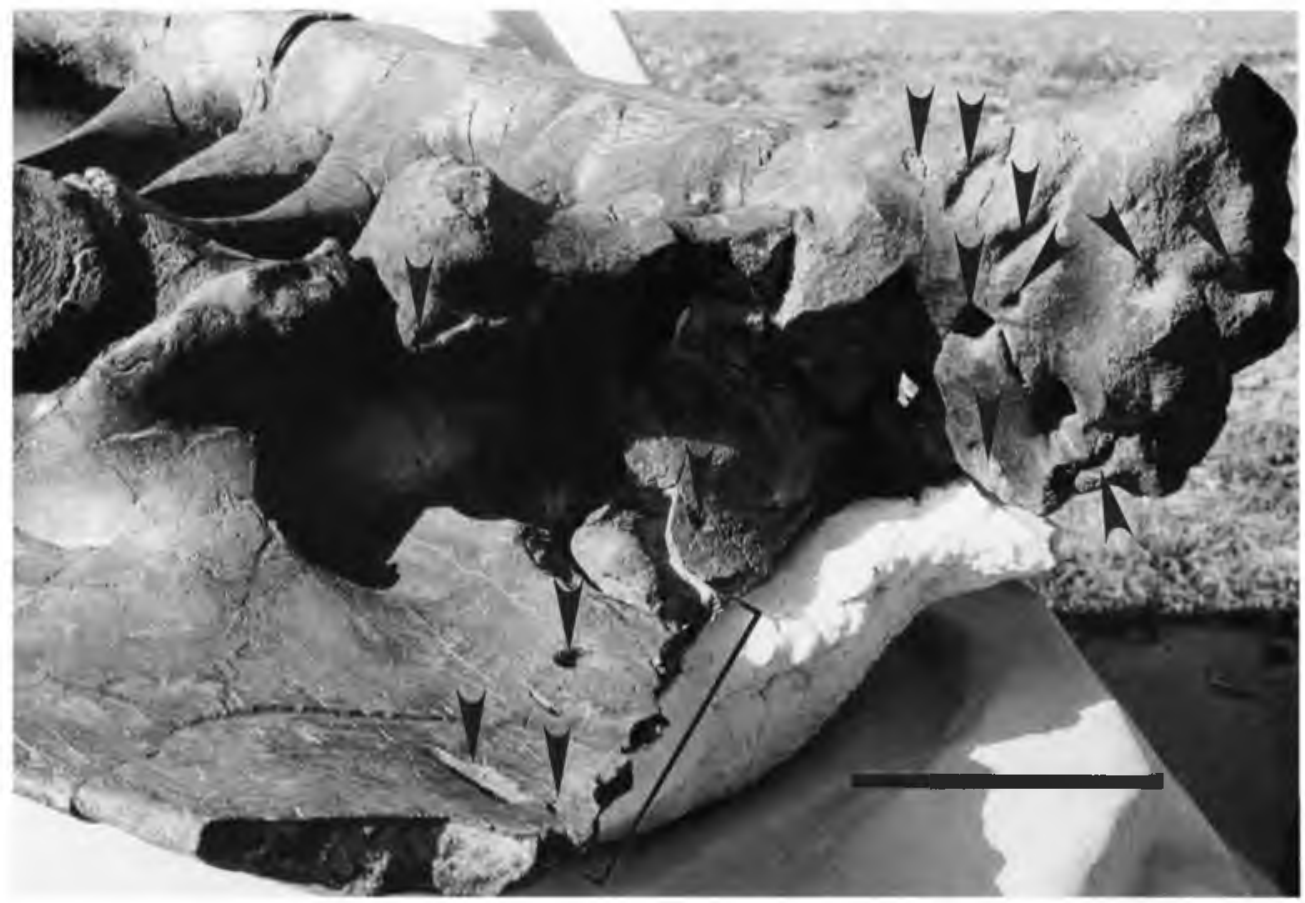

FIGURE 1. Photographs of Tyrannosaurus rex bite marks on an adult Triceratops pelvis (MOR 799). Anterolateral view of the ventral surface of the sacrum and left ilium of the specimen. Arrows point to some of the more prominent tooth marks (over 58 definitive tooth marks are present on the pelvis). Furrows from "puncture and pull" biting and deep localized punctures are visible. Brackets encompass a region where the theropod(s) removed approximately one sixth of the anterior ilium via repetitive peripheral biting. Scale $=25 \mathrm{~cm}$.

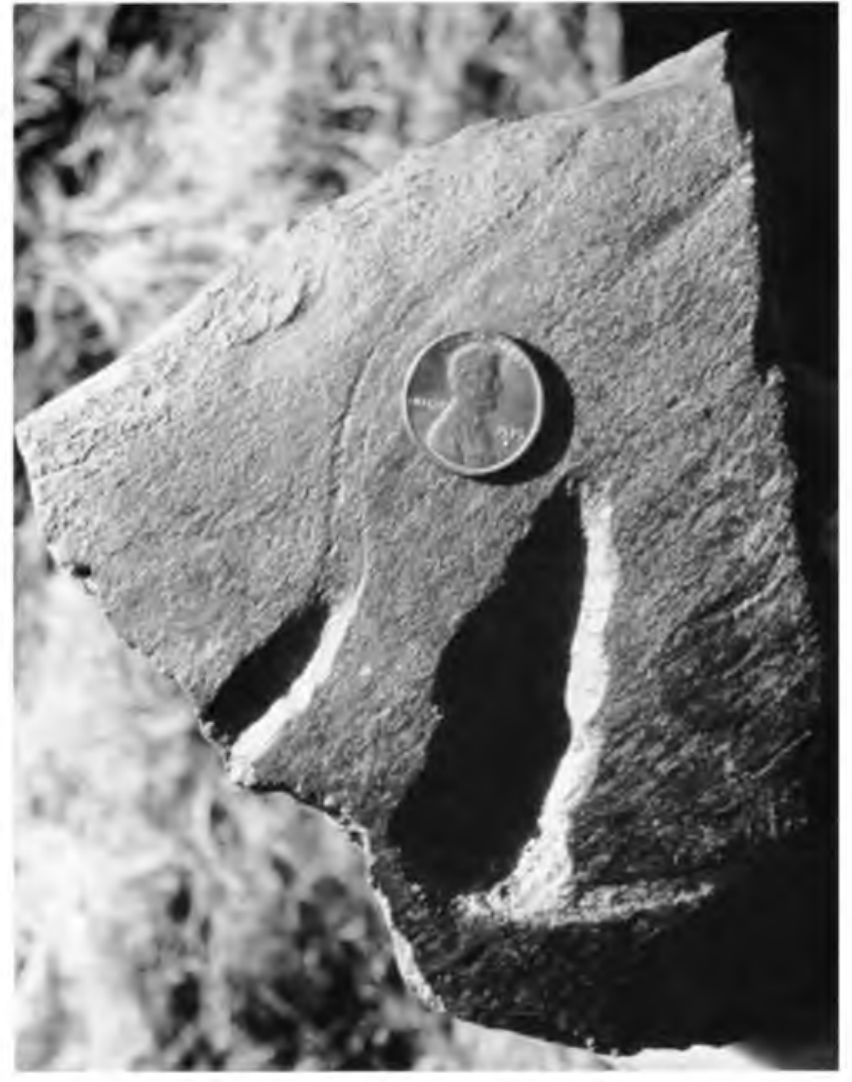

FIGURE 2. Bite mark furrows from tyrannosaur "puncture and pull" biting on the dorsal surface of the anterior iliac crest of the Triceratops pelvis (MOR 799). The initial bite penetrated the bone at the wider end of the furrow and was then dragged ascendingly toward the narrower end. tion of the Triceratops ilium and its subsequent removal, it is probable that $T$. rex ingested some bone while feeding upon carcasses. This would not be surprising because bone consumption is normal for predators; in fact it is a plesiomorphic habit for the gnathostomi. Presentday fishes and sharks (e.g., elasmobranchs), reptiles (e.g., monitors and crocodilians), birds (e.g., raptors), and mammals (e.g., canids, felids, and viverrids) all ingest some bone. Bone provides calcium and potassium for the carnivore, and these nutrients are not always available in sufficient quantities to animals that feed solely on flesh (Richardson et al., 1986). Additionally cancellous bone may contain nutrient-rich marrow, making its consumption additionally productive.

Based upon the robust morphology of tyrannosaur teeth, Bakker (1986), Farlow and Brinkman (1987), Bakker et al. (1988), Farlow et al. (1991), and Abler (1992) have inferred that bone biting may have been a common tyrannosaurid behavior. The specimens brought to light in this paper certainly confirm the physical ability of an adult $T$. rex to partake in and sustain repetitive bone biting. However, as Fiorillo (1991) has pointed out, there are relatively few reports of bite-marked dinosaur bones in the scientific literature and his surveys of museum specimens have revealed few theropod bite marks. (It is perhaps of relevance to note that Hell Creek Formation bones were not included in these surveys.) In light of these observations, is it still possible that bone biting was routine behavior for $T$. rex, as functional interpretations of its dental morphology suggest? Perhaps collection and taphonomic biases can explain this discrepancy. The following discussion highlights some of these biases that may be partly responsible for this paradox.

1. Paleontologists have traditionally collected museum display specimens, generally concentrating their efforts on skulls (Shipman, 1981) and fairly complete skeletons. Skulls may be poor candidates for bearing bite marks because they have relatively little meat (high bone/flesh ratio. see Shipman, 1981) in comparison to post-cranial elements, and fossilized entire skeletons were likely buried rapidly after death (i.e., little chance for tooth-marking). We maintain that the historically uncollected partial and isolated postcranial elements may be the bones most likely to bear bite marks (also see Fiorillo, 1991), either because they were dragged off for private consumption or because they were too big for tyrannosaur ingestion.

2. Because tyrannosaurs probably consumed all of the body parts 

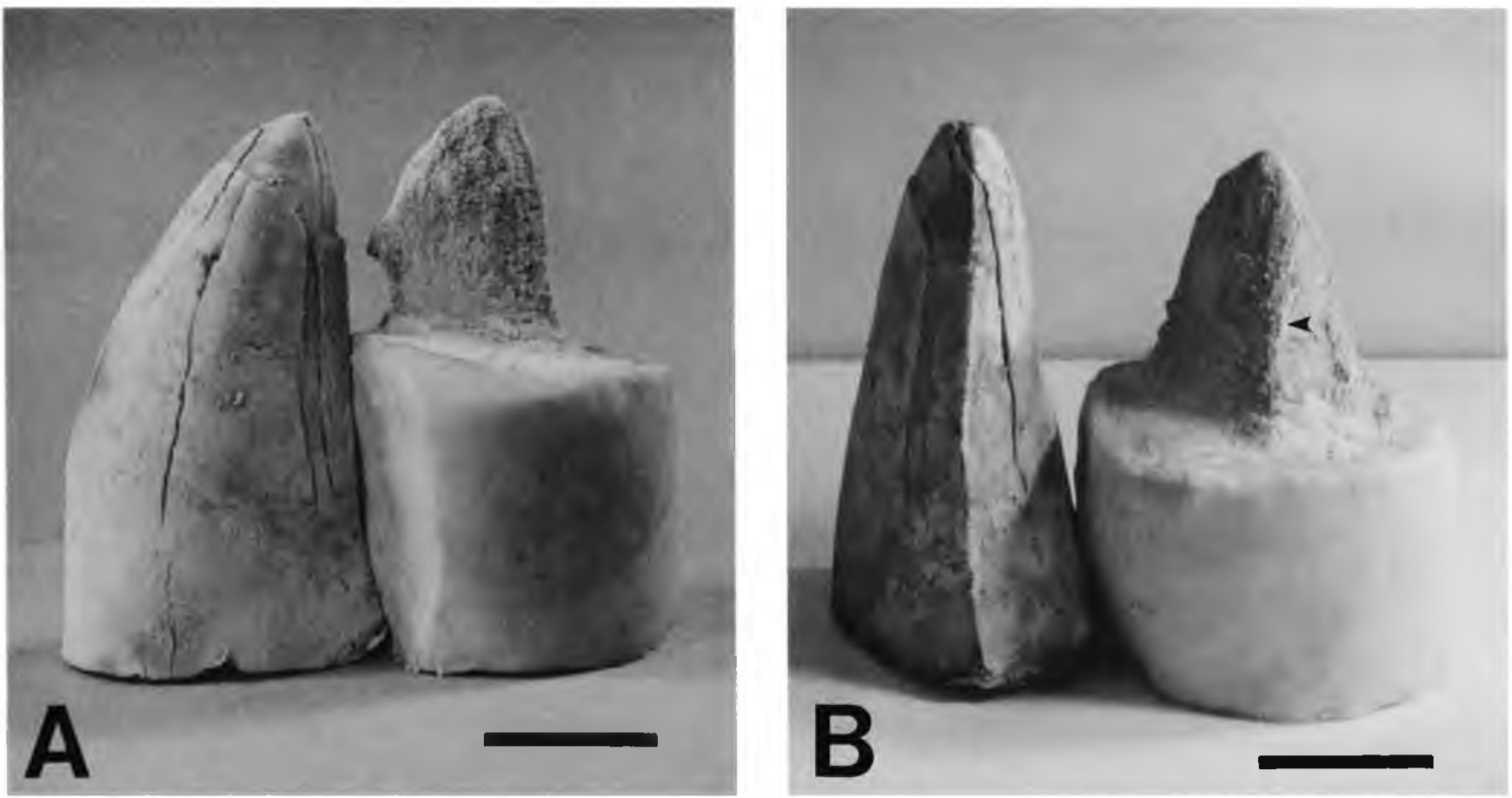

FIGURE 3. Comparison of a maxillary lateral tooth from an adult Tyrannosaurus rex (cast on left: UCMP 118742) to a cast of a puncture mark taken from the right lateral side of the Triceratops sacrum (cast on right). A, Lateral view of the tooth casts showing their similarity in size and morphology. B, Posterior view showing their similarity in size and morphology. Arrow denotes the carina on the cast from the Triceratops pelvis. Scale $=2.0 \mathrm{~cm}$

from smaller or younger prey items (Fiorillo, 1991), the bones of large adult specimens are the more likely candidates to bear bite marks. However, if tyrannosaurs were predominantly selecting smaller prey individuals, then the only opportunities for biting large bones were during rarer instances of adult predation and scavenging. Specimens of young dinosaurs are relatively rare in the fossil record (Matthew, 1915; Sternberg, 1955; Richmond, 1965; Carpenter, 1982) and theropod carnivory may partially explain this scarcity.

3. It is possible that many $T$, rex bite marks have been mistaken for natural diagenetic breaks. An adult $T$. rex probably fractured less durable bones (e.g., ribs; see Hill [1980] and Shipman [1981] for mam-

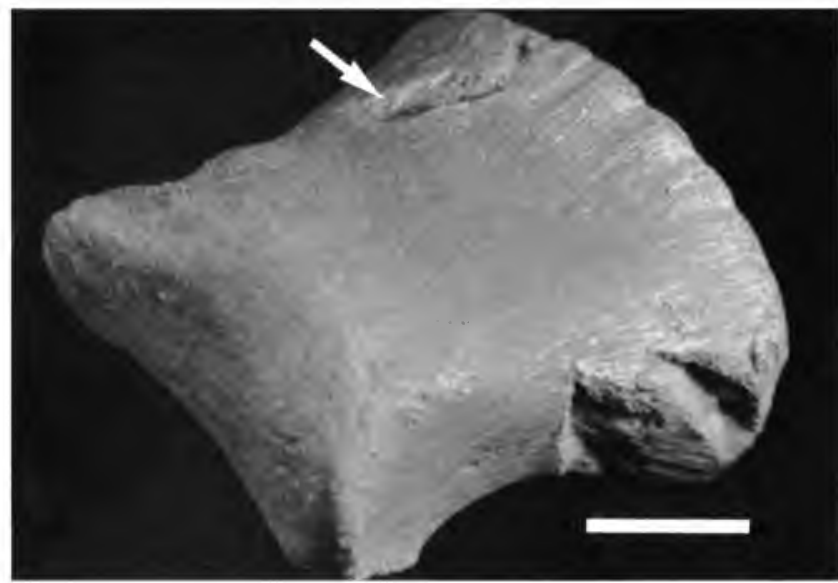

FIGURE 4. Edmontosaurus proximal pedal phalanx (UCMP 140601) bearing tyrannosaur-like "puncture and pull" bite mark furrows. The specimen bears five such bite marks (three are visible). The furrows are deeper proximally suggesting the element was somewhat articulated at the time of feeding. Scale $=2.5 \mathrm{~cm}$. malian analogies). The ragged edges and paucity of serration marks produced during some of the tyrannosaur bites on the Triceratops ilium (Fig. 1) suggest such possibilities.

4. Many collections of dinosaur remains have never been systematically examined for bite marks. An analogy may be drawn with pathological dinosaur material, of which most instances went virtually undetected until a recent resurgence in the field of paleopathology (e.g., see Rothschild and Tanke, 1992).

5. Bite-marked dinosaur bones are not generally the focus of published work, but instead are presented as interesting side-notes within papers that focus on other considerations (e.g., descriptions of new specimens, taphonomic interpretations).

6. Diagenetic processes may crack and distort bones, thereby potentially destroying bite marks of carnivorous dinosaurs. Additionally, once a bone's cortices have been cracked, either during diagenesis or by biting, it may be more susceptible to further breakdown. For example, smaller pieces of bones are generally more likely to be stream transported, and broken bones will have greater surface areas exposed to erosion, than intact bones. Crude preparatory methods can also erase bite marks from the surfaces of bones.

7. The belief that tyrannosaurs were incapable of bone biting may have discouraged some researchers from looking for tooth-marked bones or led to the dismissal of such marks as diagenetically incurred.

8. Surveys of bones from bone-beds, which often numerically dominate collections, may give the appearance that bone biting is rare for theropod dinosaurs. Bone-beds were formed in rare and unique preservational situations and their analysis should not be used to represent "normal" scavenging and bone biting behavior by extinct carnivorous animals. It is equally likely that any given bone-bed formed because of an inability of carnivorous animals (among other destructive agents) to fully utilize the carcasses. Indeterminable factors such as carnivore satiation, rotting of the flesh, inaccessibility of the bodies to scavengers (including riverbound carcasses, rapid burial, and stacked-up carcasses), a lack of carnivorous taxa in the region of the bone-bed accumulation and many other permutations all could have hindered extensive ("normal") carcass utilization 


\section{CONCLUSIONS}

Specimens of Triceratops and Edmontosaurus bear numerous bite marks attributable to $T$. rex, showing that this theropod fed upon the most common large herbivores from the Hell Creek fauna. While feeding upon mega-herbivore carcasses, $T$. rex (at least occasionally) bit deeply into bones using its larger lateral teeth. These teeth produced localized punctures or furrows, the latter of which were made during "puncture and pull" biting. It probably employed its premaxillary teeth to strip flesh from carcasses, but these teeth caused negligible damage to the bones. The serrations on $T$, rex teeth also rarely made markings on bones. The bite marks reveal that this taxon had a very robust dentition that could withstand high forces incurred during bone impacts. Bite marks from $T$. rex are supposedly rare, but this may be an artifact of collection and publication biases, the absence of systematic surveys for bite marks, a lack of knowledge of their appearance, bone consumption, loss of marks by degradation, and possible taphonomic biases.

Future studies of tooth marks are strongly encouraged for reptilian faunas, as they can reveal a great deal about the behavior, morphology, and ecology of extinct organisms, even with a minimal number of specimens to work with. Extensive studies of tooth-marked bones from prehistoric mammals (e.g., Haynes, 1980, 1983; Farlow et al., 1986; Sobbe, 1990) and fishes (e.g., Demere and Cerutti, 1982; Cigala-Fulgosi, 1990) have already demonstrated the value of such investigations.

\section{ACKNOWLEDGMENTS}

We thank J. R. Horner, P. J. Currie, J. O. Farlow, A. D. Barnosky, K. Padian, C. J. Bell, R. R. Rogers, D. Tanke, A. Roland, R. E. Molnar, K. Erickson, D. J. Varricchio, D. L. Meyer, and A. R. Fiorillo for their assistance and constructive comments pertaining to this study. This research was funded by a John D. and Catherine T. MacArthur Foundation fellowship presented to $J$. R. Horner, research grants from the National and University of California Chapters of Sigma Xi awarded to G. M. Erickson, and a travel grant to G. M. Erickson by the University of California, Museum of Paleontology.

\section{LITERATURE CITED}

Abler, W. L. 1992. The serrated teeth of tyrannosaurid dinosaurs, and biting structures in other animals. Paleobiology 18:161-183.

Auffenberg, W. 1978. Social and feeding behavior in Varanus komodoensis; pp. 301-331 in N. Greenberg and P. D. MacLean (eds.), Behavior and Neurology of Lizards. Government Printing Office, Washington D.C.

1981. The Behavioral Ecology of the Komodo Monitor. University of Florida Press, Gainesville, 406 pp.

Bakker, R. T. 1986. The Dinosaur Heresies. William and Morrow, New York, $481 \mathrm{pp}$.

-, M. Williams, and P. J. Currie. 1988. Nanotyrannus a new genus of pygmy tyrannosaur from the latest Cretaceous of Montana. Hunteria 1:1-30.

Carpenter, K. 1982. Baby dinosaurs from the Late Cretaceous Lance and Hell Creek Formations and a description of a new species of theropod. University of Wyoming Contributions in Geology 20: 123-134.

1988. Evidence of predatory behavior by Tyrannosaurus. In J. R. Horner (ed.) International Symposium on Vertebrate Behavior as Derived from the Fossil Record. Museum of the Rockies, Montana State University, Bozeman, Montana, unpaginated.

Cigula-Fulagosi, F. 1990. Predation (or possible scavenging) by a great white shark on an extinct species of bottlenosed dolphin in the Italian Pliocene. Tertiary Research 12:17-36.

Demere, T. A., and R. A. Cerutti. 1982. A Pliocene shark attack on a cetotheriid whale. Journal of Paleontology 56:1480-1482.

Farlow, J. O., and D. L. Brinkman. 1987. Serration coarseness and patterns of wear of theropod dinosaur teeth. Geological Society of America Abstracts with Programs 19:151.

$\longrightarrow,-$ W. L. Abler, and P. J. Currie. 1991. Size shape and serration density of theropod dinosaur lateral teeth. Modern Geology 16:161-198.

, T. J. McNitt, and D. E. Beynon. 1986. Two occurrences of the extinct moose Cervalces scotti from the Quaternary of Northeastern Indiana. American Midland Naturalist 115:407-412.

Fiorillo, A. R. 1991. Prey utilization by predatory dinosaurs. Palaeogeography, Palaeoclimatology, Palaeoecology 88:157-166.

Halstead, L. B., and J. Halstead. 1981. Dinosaurs. Blandford, Poole England, $170 \mathrm{pp}$.

Haynes, G. 1980. Evidence of carnivore gnawing on Pleistocene and Recent mammalian bones. Paleobiology 6:341-351.

1983. A guide for differentiating mammalian carnivore taxa responsible for gnaw damage to herbivore limb bones. Paleobiology $9: 164-172$.

Hill, A. 1980. Early post-mortem damage to the remains of some contemporary East African animals; pp. 131-152 in A. K. Behrensmeyer and A. P. Hill (eds.), Fossils in the Making. University of Chicago Press, Chicago.

Horner, J. R., and D. Lessem. 1993. The Complete T. rex. Simon and Schuster, New York, 293 pp.

Matthew, W. D. 1915. Climate and evolution. Annals of the New York Academy of Science 24:171-318.

McGinnis, H. J. 1982. Carnegie's Dinosaurs. The Board of Trustees, Carnegie Institute, Pittsburgh, 119 pp.

Molnar, R. E., and J. O. Farlow. 1990. Carnosaur paleobiology; pp. 210-224 in D. B. Weishampel, P. Dodson, and H. Osmolska (eds.), The Dinosauria. University of California Press, Berkeley, California.

Richardson, P. R. K., P. J. Mundy, and I. Plug. 1986. Bone crushing carnivores and their significance to osteodystrophy in griffon vulture chicks. Journal of the Zoological Society of London (A) 210 : 23-43.

Richmond, N. 1965. Perhaps juvenile dinosaurs were always scarce? Journal of Paleontology 39:503-505.

Rothschild, B. M., and D. Tanke. 1992. Palcopathology of vertebrates: insights to lifestyle and health in the geological record. Geoscience Canada 19:73-82.

Shipman, P. 1981. Life History of a Fossil. Harvard University Press, Cambridge, Massachusetts, $222 \mathrm{pp}$.

Sobbe, I. H. 1990. Devils on the Darling Downs-The tooth mark record. Memoirs of the Queensland Museum 27:299-322.

Sternberg, C. M. 1955. A juvenile hadrosaur from the Oldman Formation of Alberta. Annual Report, 1953-1954, Bulletin 136. National Museum of Canada 120-122.

Received 22 June 1994; accepted 14 December 1994. 